\title{
Retraction Note to: Mesenchymal stem cells seeded onto tissue-engineered osteoinductive scaffolds enhance the healing process of critical-sized radial bone defects in rat
}

\author{
Ahmad Oryan $^{1} \cdot$ Mohamadreza Baghaban Eslaminejad $^{2} \cdot$ Amir Kamali $^{1,2} \cdot$ Samaneh Hosseini $^{2} \cdot$ Ali Moshiri $^{3} \cdot$ \\ Hossein Baharvand ${ }^{2}$
}

Published online: 23 August 2021

○) Springer-Verlag GmbH Germany, part of Springer Nature 2021

\section{Correction to: Cell and tissue research (2018) 374:63-81 https://doi.org/10.1007/s00441-018-2837-7}

The Editor-in-Chief has retracted this article because it shows significant overlap with a previously published article [1]. Additionally, concerns were raised regarding a number of figures, specifically:

- Fig. 6 appears to have multiple overlapping panels with Fig. 6 of [1].

- Fig. 9 appears to have multiple overlapping panels with Fig. 9 of [1].

The Editor-in-Chief therefore no longer has confidence in the reliability of the data reported in the article.

Ahmad Oryan disagrees to this retraction. Mohamadreza Baghaban Eslaminejad, Amir Kamali, Samaneh Hosseini, ali Moshiri and Hossein Baharvand have not responded to correspondence regarding this retraction.

The original article can be found online at https://doi.org/10.1007/ s00441-018-2837-7.

Ahmad Oryan

Oryan@ shirazu.ac.ir

Mohamadreza Baghaban Eslaminejad

Eslami@royaninstitute.org

1 Department of Pathology, School of Veterinary Medicine, Shiraz University, Shiraz, Iran

2 Department of Stem Cells and Developmental Biology, Cell Science Research Center, Royan Institute for Stem Cell Biology and Technology, ACECR, Tehran, Iran

3 Department of Surgery and Radiology, Dr. MoshiriVeterinary Clinic, Tehran, Iran

\section{References}

Oryan A, Baghaban Eslaminejad M, Kamali A, Hosseini S, Sayahpour FA, Baharvand H (2019) Synergistic effect of strontium, bioactive glass and nano-hydroxyapatite promotes bone regeneration of critical-sized radial bone defects. J Biomed Mater Res Part B 107B:50-64

Publisher's Note Springer Nature remains neutral with regard to jurisdictional claims in published maps and institutional affiliations. 